\title{
Capsule Commentary on Gonzalo et al., Patient-Centered Interprofessional Collaborative Care: Factors Associated with Bedside Interprofessional Rounds
}

\author{
David V. Evans, MD \\ Department of Family Medicine, University of Washington School of Medicine, Seattle, WA, USA.
}

J Gen Intern Med 29(7):1057

DOI: $10.1007 / \mathrm{s} 11606-014-2851-8$

(c) Society of General Internal Medicine 2014

$\mathrm{G}$ one are the days of a sagely white-haired diagnostician leading a team of learners to a patient's bedside and extolling wisdom to his attentive listeners. Today's rounds are more likely to take place in a hallway or conference room with a computer at center stage instead of the patient. ${ }^{1}$ This occurs despite the fact that patients prefer to interact with the care team at the bedside. ${ }^{2},{ }^{3}$ In the article "PatientCentered Interprofessional Collaborative Care: Factors Associated with Bedside Interprofessional Rounds", Gonzalo et al. examine factors that promote bedside interprofessional rounds (BIR). ${ }^{4}$

The Affordable Care Act and the potential emergence of more patient-centered and quality-based care are bringing increased attention to the benefits of collaborative care. Healthcare that intentionally includes doctors and other health professionals results in increased care coordination, shared decision making, and communication, all of which are important to meeting the Institute of Healthcare Improvement's Triple Aim of improving the patient experience (quality and satisfaction), improving health of populations, and reducing costs.

Gonzalo and colleagues in an observational study of 412 rounding encounters with 25 attending physicians found that BIR occurred in $64 \%$ of rounding encounters and was more likely to take place if the census size was less than 12 , the attending had less than 5 years of experience (compared to attendings with more than 16 years of experience), a senior resident was on the team, or rounds occurred on a weekday.

Interprofessional education and patient-centered care deserve increased attention, as there is ample evidence that health care delivered by multidisciplinary teams improves outcomes. ${ }^{5}$ Gonzalo's study is the first to examine what factors make BIR more or less likely to occur. There was no data provided on patient-centered outcomes, such as patient satisfaction and no data on learner perceptions of the effectiveness of these rounds. This research offers medical educators interested in maximizing patient-centered interprofessional care the opportunity to anticipate areas of challenge and make more informed decisions about program implementation. The best news that emerges from this study is that bedside rounds are still being conducted regularly.

Conflict of Interest: The author has no conflict with any of the material in this manuscript

Corresponding Author: David V. Evans, MD; Department of Family MedicineUniversity of Washington School of Medicine, Box 356390, Seattle, WA 98195, USA (e-mail: evansd9@uw.edu).

\section{REFERENCES}

1. Gonzalo JD, Masters PA, Simons RJ, Chuang CH. Attending rounds and bedside case presentations: medical student and medicine resident experiences and attitudes. Teach Learn Med. 2009;21(2): 105-110.

2. Lehmann LS, Brancati FL, Chen MC, Roter D, Dobs AS. The effect of bedside case presentations on patients' perceptions of their medical care. N Engl J Med. 1997;336(16): 1150-1155.

3. Gonzalo JD, Heist BS, Duffy BL, et al. The value of bedside rounds: a multicenter qualitative study. Teach Learn Med. 2013;25(4):326-333.

4. Gonzalo JD, Wolpaw DR, Lehman E, Chuang CH. Patient-centered interprofessional collaborative care: factors associated with bedside interprofessional rounds. J Gen Int Med 2014. doi:10.1007/s11606-014-2817-x.

5. Schmitt MH, Gilbert JHV, Brandt BF, Weinstein RS. The coming of age for interprofessional education and practice. Am J Med. 2013;126(4):284288 . 